\title{
"PÉTALOS": OLFATO Y OBSESIÓN DE CARÁCTER MONSTRUOSO
}

Andrés Leal Gil - Helen Hernández Páez 


\section{"PÉTALOS": SMELL AND OBSESSION OF MONSTROUS CHARACTER}

\section{RESUMEN}

Esta reflexión no indaga lo monstruoso en términos de deformidad, sino que rastrea aquello que puede y constituye un ser monstruoso. Del mismo modo, se exploran las relaciones dadas entre el cuerpo, sus olores y los valores asignados a estos a través de la normalidad, en un intercambio dialógico de lo humano, lo inhumano y lo animal, en otras palabras, de lo configurado como monstruoso. Para tejer estos planteamientos, se toma como referencia el cuento "Pétalos" de la mexicana Guadalupe Nettel, en el cual lo monstruoso, vinculado al cuerpo, toma preponderancia por medio del sentido del olfato y olores escatológicos. Se apartará a lo monstruoso de su noción reducida; por el contrario, se abordará en su vínculo con el pensamiento filosófico y arqueológico de diversos autores, como Michel Foucault, David Le Breton, Jean Luc Nancy y Friedrich Nietzsche, con el fin de identificar y localizar puntos de convergencia que arrojen nuevas perspectivas y maneras de abordar la complejidad del cuerpo y los olores que lo configuran alrededor de lo monstruoso.

Palabras claves: "Pétalos", cuerpo, monstruoso, normalidad, olfato.

\section{AUTORES}

\section{Andrés Leal Gil}

Maestro en Artes plásticas y visuales

Universidad del Tolima

Correo: andresleal2713@gmail.com

Helen Hernández Páez

Estudiante de Licenciatura en Lengua castellana

Universidad del Tolima

Correo:hyhernandez@ut.edu.co

\section{ABSTRACT}

This reflection does not investigate the monstrous in terms of deformity, but traces what is and could be a monstrous being. In the same way, the relations between the body, its odors and the values assigned to them through normality are explored in a dialogical exchange of the human, the inhuman and the animal. In other words, of what is configured as monstrous. So, the story "Petals", written by the Mexican Guadalupe Nettel, is taken as a reference to weave these approaches, in which the monstrous linked to the body, takes precedence by the sense of smell and eschatological smells. The monstrous will be separated from its reduced notion; on the contrary, it will be approached as a link to the philosophical and archaeological thought of various authors such as Michel Foucault, David Le Breton, Jean Luc Nancy, and Friedrich Nietzsche; in order to identify and locate points of convergence that throw new perspectives and ways of approaching the complexity of the body and the smells that configure it around the monstrous.

Key words: "Petals", body, monstrous, normality, smell.
Recibido: 21 de febrero 2018

Aprobado: 2 de mayo 2018 
No veía, oía y sentía nada, sólo percibía el olor que le envolvía.. Patrick Süskind (1997)

\section{INTRODUCCIÓN}

Ante las complejidades y contradicciones que presentan el cuerpo, los olores y los modos de habitar y de coexistir con otros cuerpos, nuestra intención es generar reflexiones y preguntas, mas no ofrecer respuestas claras y argumentos concisos que respondan, verdaderamente, qué es aquello que constituye un cuerpo monstruoso. Proponemos un ejercicio de escritura y pensamiento, una conversación con filósofos cuyas reflexiones se aproximan a eso que nos inquieta. Una resonancia, desde la literatura, que a través de la narración "Pétalos", escrita por la mexicana Guadalupe Nettel' ${ }^{1}$, nos adentra a una realidad en donde el protagonista principal, cuyo nombre nunca es mencionado, se obsesiona por una mujer, luego de percibir su olor, no el de un perfume o el de sus cabellos: su obsesión radica en perseguirla por medio de sus excrecencias. La busca en los baños de restaurantes, bares y cafés y el punto de encuentro con aquella mujer, que llama "la flor", son los sanitarios públicos y todo lo relacionado con los olores escatológicos.

Las relaciones que, desde las narraciones literarias, se tejen entorno al cuerpo y lo monstruoso brindan una perspectiva en la cual lo monstruoso sobrepasa los límites biológicos que lo asocian a la deformidad (Calabresse, 1999). "Pétalos", ubicado en esos límites, permite ver cómo la literatura muestra otras maneras de abordar y de concebir el cuerpo y lo monstruoso. La construcción literaria del personaje no deja de ser un pretexto para adentrarse en dichos conceptos, por medio de teóricos como Michel Fou- cault, que, en sus numerosas reflexiones acerca del poder, y de su incidencia en las conductas humanas y su regulación, construye una teorización alrededor de lo que él identificó como anormales. Estos referieren a personajes próximos a lo que puede considerarse como monstruoso, puesto que su relación con la realidad y el cuerpo no se encuentra sujeta a las normativas sociales impuestas, sino que, por el contrario, se encuentran permanentemente imbuidos en un ir más allá de sus límites corporales y psicológicos; por lo que son señalados y castigados.

Foucault deja claro que siempre se trata del cuerpo. Por esto, voces como las de Le Breton, Jean Luc Nancy y Nietzsche aportan nuevas ideas y concepciones que giran en torno al cuerpo, a sus nuevas construcciones, a los valores que se le asignan en la modernidad y cómo el ser humano se involucra en esas dinámicas que terminan por fragmentar, acusar y negar todas las dimensiones del cuerpo.

\section{EL OLFATO Y LO MONSTRUOSO}

El olfato es un sentido relevante, que posee diversas connotaciones en el cuento "Pétalos", dado que establece una relación directa entre el cuerpo y su representación alrededor de lo monstruoso. En esta narración, lo olfativo (por medio del personaje principal) se muestra más allá de su función anatómica y biológica: devela la exploración de múltiples posibilidades, que sobrepasan aquellas condiciones evidentes y las amplían. De esta manera, lo cotidiano e intrascendente adquiere una dimensión en la cual se pueden hacer lecturas que implican reconocer otras maneras de abordar las relaciones sociales, éticas, morales y, por supuesto, estéticas.

\footnotetext{
$1 \quad$ Nettel, licenciada en Letras hispánicas por la Facultad de Filosofía y Letras de la UNAM, ha sido galardonada con diversos premios, entre los cuales se destacan el Premio de Narrativa Breve Ribera del Duero (2006), el premio franco-mexicano Antonin Artaud (2008) y el Premio Nacional de Cuentos Gilberto Owen (2007).
} 
En la actualidad, en Occidente, los sentidos en general son relegados, por no decir neutralizados o, peor aún, anestesiados. Todos menos uno, que marca el derrotero cultural e ideológico puesto que genera cánones morales, éticos y estéticos, este sentido es la vista. El culto a la vista silencia los demás sentidos; de este modo, las palabras de santo Tomás toman un significado de autoridad: "ver para creer" (1960, p.1007). Lo que se ve es lo real, de esta manera se determina qué es lo bello, lo feo, lo monstruoso y lo normal. Todo esto se da a partir de la visión. Esto no quiere decir, por supuesto, que en Occidente no se huela, no se oiga, no se escuche, no se deguste y no se toque. ¡Sí!, sí se huele, se oye, se escucha, se degusta y se toca; pero todo ello se hace desde la visión.

Lo normal, en este contexto, es mediar todos los sentidos a través de la vista y, de esta manera, anular lo singular y lo carente de homogeneidad. No obstante, ¿qué sería entonces lo anormal?, ¿alguien que intente con su sentido del olfato oler, como el personaje principal de "Pétalos"?, ¿acaso, para nosotros, lo único normal es servirse de la visión?, ¿excedernos con nuestros demás sentidos nos convierte en monstruos? No siempre lo monstruoso se vincula con adjetivos de malo, feo, disfórico o deforme. Así lo plantea Calabrese (1999), quiene, valiéndose de su etimología, monitum, expone que lo monstruoso no es lo imperfecto, sino aquello que intenta ir más allá de lo que es, aquello "[...] que sobrepasa los confines de esa medida media que distingue la otra perfección" (1999, p.107). En otras palabras, aquello que no se encuentra encasillado en lo usual: eso es lo monstruoso. Foucault (2000) enfoca el problema de aquellos individuos que sobrepasan sus capacidades y se exponen al límite, como seres a quienes en el siglo XIX se denominó anormales.

Foucault (2000) plantea tres figuras principales cuando se refiere a dichos individuos: el incorregi- ble o inadmisible, el masturbador y el monstruo. Las implicaciones de todo ello conducen a la normalización. Lo normal, entonces, es aquello que no está más allá de los límites y que encaja en un imaginario colectivo, además, se establece como una contraposición respecto a lo denominado monstruoso. Lo normal es aceptado, mientras lo monstruoso se rechaza de manera exacerbada. Lo monstruoso es antitético, antiestético e inmoral; es la acusación prefabricada para todo aquel que quiera ampliar su percepción, como darle apertura a los sentidos (así sea uno solo); es la bienvenida a nuevas concepciones y construcciones de la realidad y del mundo. Por ello, Foucault, cuando se refiere al monstruo, le asigna siempre el adjetivo de humano. Los monstruos no son gigantes, minotauros o seres sobrenaturales, el monstruo es alguien de dimensión humana, como cualquiera de nosotros, es el que transgrede las nociones y los marcos de referencia. Dirá Foucault: "el monstruo es lo que combina lo imposible y lo prohibido" (2000, p.61).

En la narración "Pétalos", a través de su olfato, el personaje principal sobrepasa el límite de lo biológico y lo impuesto cultural y moralmente. Por esta razón, es considerado monstruoso, es decir, anormal. Su vínculo con la realidad es exaltar el cuerpo de su amante, no por su belleza, sino, precisamente, por aquello que todo persona normal busca ocultar. Es anormal por amar de otras maneras, por sentir y afirmarse desde el olfato, elemento aún no mediado por la sanción normalizadora y las fuerzas productivas.

El cuerpo humano se encuentra dotado para explorar el mundo a través de los sentidos: tocar, oír, degustar, oler y, naturalmente, mirar; no obstante, pareciera que la única interpretación aceptable es la realidad visual. Una interpretación olfativa es prohibida (igual que la sonora y la táctil), puesto que no se encuentra normalizada, ni parametrizada. Esta permite una configu- 
ración diversa de la realidad, que hasta el momento no se halla controlada. El protagonista de "Pétalos" es monstruoso porque, con su capacidad olfativa, llega al punto de inferir cómo es alguien físicamente o qué problemas de salud y estados de ánimo puede presentar. Es monstruoso porque es alguien excepcional por su carácter de rareza. Si a dicho personaje se le encontrase caminando por algún restaurante o bar, sería considerado monstruoso, e intervendría el dispositivo de la psiquiatría, desde una posición normalizadora, o el aparato penal.

\section{OLORES ¿MONSTRUOSOS?}

Los olores direccionan una ruta en la cual se puede determinar qué dinámicas rigen una sociedad e, incluso, establecer un plano moral suficiente para comprender las relaciones que se tejen. A partir de cómo huele una sociedad, de qué olores establece como cánones, se puede inferir cuál y cómo es la manera de abordar el cuerpo, lo normal y, en general, la vida.

La posición hegemónica que posee la visión le ha asignado al olfato un lugar marginal, por ser el órgano de los sentidos que se asemeja más a lo animal. Es propia de ellos la tendencia a olfatear las comidas, las deposiciones, los organismos en estado de descomposición. La visión hace parte de un ser civilizado, mientras que el olfato le pertenece al animal. Corbin (1987) afirma que gran parte de esta segregación viene heredada de la medicina, más específicamente de la higiene: lo normal se estableció por un espacio médicamente útil. Foucault (1976) señala que las disposiciones de vigilancia proceden de la observación médica. Con los cuerpos y los olores proceden de la misma manera que con los medicamentos: los encierran, los clasifican y los estudian. La clínica establece la norma, es decir, lo que es normal, que, en este contexto, es negar el cuerpo con todas sus dimensiones. Quien sea animal (aunque somos animales), quien huela como ellos, se convertirá inmediatamente en un monstruo, "un monstruo humano-animal".

La clasificación de los olores, en primer lugar, destaca "lo positivo", aquello que comúnmente se considera oler bien, por su referencia a lo vivo y fresco. Por su parte, los "olores negativos" se asocian más a lo dañado, degradado o muerto. Los olores exigen un estándar moral y estético que los jerarquiza y les asigna un valor. Surgen como un dispositivo de vigilancia, un procedimiento que sirve para medir, dominar, organizar y, sobre todo, sancionar. Si existen olores sutiles, suaves y dulces que determinan un cuerpo bello, socialmente concebido como normal, cuyas posiciones morales son duales y dogmáticas, ¿qué sucede con los olores desagradables y escatológicos que configuran un cuerpo grotesco, socialmente "anormal" e "inestable" y moralmente asumido como algo maligno?

\section{CUERPOS ¿MONSTRUOSOS?}

El cuerpo pareciese algo evidente y concreto, un organismo con una forma determinada. No obstante, nada resulta tan inaprensible como él. Siempre se trata del cuerpo. Todo recae en él: lo cercan, lo marcan, lo doman, lo someten, lo fuerzan, lo obligan. Hablamos de su conciencia y espíritu, o en algunos casos de su alma, pero ni siquiera sabemos "lo que puede -como lo dijo Spinoza- un cuerpo" (Spinoza, citado por Deleuze, 1971, p.59).

Todo lo que puede nuestro cuerpo es monstruoso. Esta noción es consecuencia del alejamiento de la visión platónica occidental, la cual marca un abismo entre el hecho de ser y de poseer un cuerpo. Nettel exalta en sus narraciones la monstruosidad, al explorar el cuerpo en todas sus dimensiones, al no negar la diversidad de los elementos que lo componen. Quienes niegan el cuerpo son aquellos que solo desarrollan su olfato para los olores "positivos", su 
cuerpo es, en palabras de Nancy (2008), un diseño o, en palabras de Foucault (1976), un cuerpo-máquina, que se encuentra inmerso en una economía política que calcula sus gestos, comportamientos, gustos, y "lo hace tanto más obediente cuanto más útil” (p.160). De esta manera aniquila la posibilidad de errar, fracasar y sentir, en cambio, se constituye como un instrumento, un objeto de trabajo. Así, se olvida aquello que nos dice Nancy: "los cuerpos son todos algo deformes. Un cuerpo perfectamente formado es un cuerpo molesto, indiscreto en el mundo de los cuerpos, inaceptable" (2010). Es el cuerpo propio de una máquina.

Las máquinas fabrican siempre cuerpos que huelen de la misma manera y que no quieren, de ningún modo, reír, sudar o excretar. Nettel configura el personaje principal de "Pétalos" como aquel que, justamente, desafía aquellas dos maneras de ver el cuerpo (como un diseño o una máquina) y, por el contrario, exalta su deformidad y converge con la reflexión que propuso Nancy (2008): "no tenemos un cuerpo sino que somos un cuerpo" (p.4). La deformidad de aquel personaje lo hace ser diferente: su olfato y su cuerpo no son iguales, no son fabricados $y$, por tanto, tienen singularidad. Por esta razón nos resultan monstruosos.

La monstruosidad permite configurar un cuerpo grotesco, que lo es no por su extravagancia y fealdad, sino por su desbordante vitalidad. El protagonista asume su cuerpo como "abierto e insatisfecho con los límites que permanentemente trasgrede; como un cuerpo que nunca deja de renacer" (Le Breton, 2002 , p.31). Le Breton plantea también que el cuerpo moderno se opone radicalmente al cuerpo grotesco, dado que no posee parámetros con los cuales analizar, controlar y manipular su conducta. En otras palabras, el cuerpo grotesco es algo enigmático, por ello resulta anormal. El cuerpo grotesco, dice Bajtín
(1987), "no tiene una demarcación respecto del mundo, no está encerrado, terminado, ni listo, sino que se excede a sí mismo, atraviesa sus propios límites" (p.35). Un cuerpo monstruoso no es, entonces, el que pertenece a las fuerzas del mal, sino el que asume su cuerpo y sabe, en todas las dimensiones, que es grotesco, pues suda, excreta, ríe, posee olores que no son aceptados y no se limita a ocultarlos, sino que los expone $y$, en este caso, surge un enamoramiento hacia una mujer, no por su piel tersa o protuberantes pechos, sino por el olor de sus execrencias, de lo denigrante del cuerpo, de lo que (casi) todo el mundo pretende evadir.

En "Pétalos", el cuerpo se configura como monstruoso porque en él recaen las dimensiones de los olores de orden "negativo", que crean un sentimiento de insatisfacción, mientras que los cuerpos-máquinas o los diseños fabricados, viven en la conformidad de lo conocido. Esta imposibilidad lleva al cuerpo al límite y, a su vez, a que no se debata en dualidades ni en aspectos morales. El protagonista frecuenta sanitarios de diversos bares, restaurantes y cafés, impulsado por una fuerza incontrolable que en ningún momento pretender explicar ni, mucho menos, controlar. Esta fuerza lo mueve, lo impulsa a desear, a mantener vivas, justamente, la insatisfacción y la curiosidad por los olores.

Nietzsche (1999), por ejemplo, cuando se refirió al cuerpo, confesó que no era un hombre sino un campo de batalla. Por su parte, Foucault (1976) manifestó que todo cuerpo es un campo de fuerzas, es decir, que el cuerpo es movimiento que no se oculta, ni se fragmenta $y$, en esa medida, se configura lo monstruoso. Nietzsche lo era, ciertamente. Su filosofía fue siempre la exaltación del cuerpo como vitalidad: el filósofo de la vida por excelencia siempre puso al cuerpo como actor principal y acusó poéticamente a los despreciadores de la vida, a todos aquellos 
que negaban el cuerpo. A través de sus palabras, se encargó de recuperarlo, de potenciarlo y recubrirlo de una vitalidad, la cual había sido despojada por la moral cristiana y, de paso, por sistemas filosóficos y de pensamiento. De similar modo procede Nettel con la configuración de su personaje, el cual se expone, no con la razón, sino con su cuerpo, lo afirma como punto de partida $y$, si se quiere, también de llegada. Tal personaje exacerba uno de los sentidos y lo expande a todo lo que acaece en su cuerpo, lo atraviesa y lo transforma. Todo allí acontece. Es atravesado por múltiples fuerzas, activas y reactivas (Deleuze, 1971). El cuerpo nos presenta la vida con todas sus paradojas, contradicciones, racionalidades e irracionalidades, relaciones individuales, colectivas y animales.

Frente a esto, de manera implícita, el cuerpo es el principal objetivo a controlar, dada su multiplicidad e inestabilidad. Sin embargo, con Nietzsche y con la narración propuesta por Nettel, se dimensiona que un cuerpo no logra estar siempre en silencio.

\section{A MODO DE CIERRE}

El cuerpo es monstruoso por naturaleza, pero se normaliza al considerar la visión como único sentido posible para interpretar o vivir. Todo lo que puede nuestro cuerpo es monstruoso. Asumirlo va más allá de poseerlo como una pertenencia o valerse de él, es, sobre todo, no medirlo, ni tazarlo bajo una mirada moralista repleta de prejuicios ni, en otro caso, a la sombra de una mirada científica. ¡No! Asumir el cuerpo es, precisamente, valorar su multiplicidad, apreciar sus dimensiones; saber que cambia, que envejece, que se degrada y muere y que en eso radica su belleza y su potencia. Recodando las palabras de Nietzsche (1999), "detrás de tus ideas y sentimientos se oculta un poderoso señor, un sabio desconocido: reside en tu cuerpo, es tu cuerpo" (p.56).
Sentir repulsión por ciertos olores es una negación esencial. Sentir aversión por determinados olores, como el del excremento, de organismos en estado de descomposición, o cualquier olor pútrido o no aceptado socialmente, es la negación de aquello inherente del cuerpo. Negarlo, precisamente, es la contraposición de lo manifestado por Nettel en su narración "Pétalos", pues toda negación de los sentidos es una negación de la vida.

\section{REFERENCIAS}

Bajtín, M. (1987). La cultura popular en la edad media y el renacimiento. Madrid: Alianza Editorial.

Calabrese, O. (1999). La era neobarroca. Madrid: Cátedra.

Corbin, A. (1987). El perfume o el miasma: el olfato y el imaginario social siglos XVIII y XIX. Madrid: FCE.

Deleuze, G. (1971). Nietzsche y la Filosofía. Barcelona: Anagrama.Foucault, M. (1976). Vigilar y castigar: nacimiento de la prisión. Buenos Aires: Siglo XXI Editores.

Foucault, M. (2000). Los anormales. México: FCE.

Le Breton, D. (2002). Antropología del cuerpo y modernidad. Buenos Aires: Ediciones Nueva Visión.

Nancy, J. L. (2008). Las metáforas del cuerpo en la filosofía de Jean-Luc Nancy. Recuperado de: http:// pendientedemigracion.ucm.es/info/nomadas/18/ avrocca2.pdf.

Nancy, J. L. (2010). '58 indicios sobre el cuerpo', fragmento. Recuperado de: http://preferirianohacerloradio.blogspot.com/2010/07/audio-del-programasobre-los-indicios.html

Nettel, G. (2008). Pétalos y otras historias incómo- 
das. Barcelona: Anagrama.

Nietzsche, F. (1999). Así habló Zarathustra. Madrid: Biblioteca Contemporánea.

La santa Biblia. (1960). Bogotá: Sociedades Bíblicas Unidas.

Süskind, P. (1997). El perfume. Barcelona: Seix Barrial. 